\title{
ANALYSIS OF MICRO LEVEL DISPARITIES IN URBAN FACILITY-UTILITY SERVICES: A STUDY ON BARASAT CITY, WEST BENGAL, INDIA
}

\author{
Suman PAUL \\ Krishnagar Govt. College, Krishnanagar, India
}

\begin{abstract}
The regional disparity is a challenging issue to the urban planners, policy makers, academicians, bureaucrats and technocrats in the developing countries. In India, wide range of socio-economic disparities are commonly evident even in Class-I cities. Such an undesirable phenomena reflects on the spatial variation of quality of life, level of living as well as well-being and welfare of the inhabitants. Moreover, it is against the constitutional law of equity and social justice. The present study is based on the empirical observation focused on ward-wise variation of availability of and accessibility to socioeconomic and utility services in Barasat city of West Bengal. On the basis of 'Cronbach's Alpha' and 'Principal Component Analysis', entire set of data have been arranged into six factors of which first three factors have been considered to examine the dimension of socio-economic disparities and level of development in the city.
\end{abstract}

Key Words: disparity, utility services, Cronbach's Alpha, principal component analysis

\section{Introduction}

The development of socio-economic infrastructure and urban facility-utility facilities indicate the quality of life of the people of a particular area. The availability of all socio-economic infrastructures is solely not meant for the development until and unless it is adequately available corresponding to the population size and extent of area. Such an adequacy should ensure the accessibility to socio-economic infrastructure by the people. But, unfair political practices, physiographic characteristics and socio-cultural dogma have resulted into the unequal and irrational distribution of infrastructure in the region leading to the emergence of regional disparities. Regional disparity comes into being when any state fails to an extent to meet up with the distribution of developmental fruits equitably to all corners of the region. An unchecked and uncontrolled process of growth leading to the regional disparities may result in economic, social and cultural problems (Hungaragi 2008). The coexistence of developed and underdeveloped regions in a country or state leads to misallocation and underutilization of resources with untapped potential of some areas. Such disparities are not conducive to regional development (Kumar 2009). It is a characteristic phenomenon of developing economy. The poor countries of the world are characterized by large and growing regional disparities while rich countries are generally characterized by small and diminishing gaps in development (Williamson 1965).

Inequalities at the level of development have been an integral feature of the history of India's economic development. The magnitude of regional disparity became wide during the British colonial period, which for their own business interest developed few port areas leaving other 
parts of India most backward. After independence in 1947, a considerable emphasis was given to eliminate this problem. In the Third Five Year Plan (1961-'66) a separate chapter was devoted to balance regional development (Chapter IX). Policies for the development of backward areas, at the centre and state levels, identification of backward areas and indicators of development for different sector etc., all the efforts were made based on Pandey Committee, Chakraborty Committee and National Council for Development of Backward Areas (NCDBA) recommendation right from the Third Five Year Plan (Kumar, 2009). Despite different efforts being undertaken, India still has been experiencing a wide inter as well as intra regional disparities both at macro and micro level in socio-economic and cultural development.

Several studies on the examination of magnitude of regional inequality have been made inbroad and India as well.

Different scholars like Mathur (1983) and Dadibhavi (1998) tried to access the regional disparities in socio-economic development using per capita income as a measure of development. Rao (1985) analysed the extent of inter-state disparities in development measured on the basis of per capita state domestic product. A group of scholars like Rao (1984), Rao and Babu (1996), Soen et al. (1997), Mallikarjun (2000), Hassan (2007) and Paul (2012) attempted to focus on the leading factors of regional disparities of different socioeconomic development by adopting Principal Component Analysis and Composite Index techniques. Sao Suman (2007), Paul and Dasgupta (2008), Rahaman and Salauddin (2009) and Deepika Varshney et al. (2010) tries to find out the nature of and determinants of disparities of urban utility-facility services in intra ward variation of urban centres.

A review of the studies on the issue of regional disparities reveals that most of the studies are based on broad area and restrained from the study at smallest unit like ward level in the city. Hence, the paper is an attempt to examine the spatial distribution of facility-utility services and inter-ward disparities in levels of socio-economic development of Burdwan city.

\section{Study Area}

Barasat Municipality was born on 1st April 1869 but up to 1882 it did not have any independent existence. Like other offices it was controlled by Magistrate Office; during that time there was no Chairman of the municipality, Magistrate was the Controller of municipality. Later on after 1882 Barasat Municipality had got its own formation as an autonomous body and became local government. Barasat Association, a citizens organization, had helped Barasat Municipality by donating land for the construction of municipal building. Total Barasat municipal area was divided in to 30 Wards. Previously, there were 4 Wards and after that 18 Wards under Barasat Municipality. Later on after amalgamating surrounding Panchayat within Barasat Municipality in 1995, at present Barasat Municipality has 30 Wards.

Barasat town is the district headquarter of North 24 Parganas district and junction corridor of North Bengal and Bangladesh. The growth of population of this town is very high that is $3.5 \%$ per year. As per 2001 census the population of this town was 231,521 and now it is 275,000 (approx) and the projected population by the year 2025 it will be 525,000. The total municipal area of Barasat covers $34.50 \mathrm{sq}$. km. Barasat town it well connected with roads to Kolkata, North Bengal, Bangladesh and other towns of West Bengal. The two National Highways (NH 34 \& $\mathrm{NH} 35$ ) and one State Highway (SH 2) run through Barasat town; Barasat is also well connected by railway with Sealdah, Bongaon and Basirhat.

At present one railway over bridge $(\mathrm{ROB})$ is under construction for easy traffic way within 
Analysis of Micro Level Disparities in Urban Facility-Utility Services: a Study on Barasat City, West Bengal, India

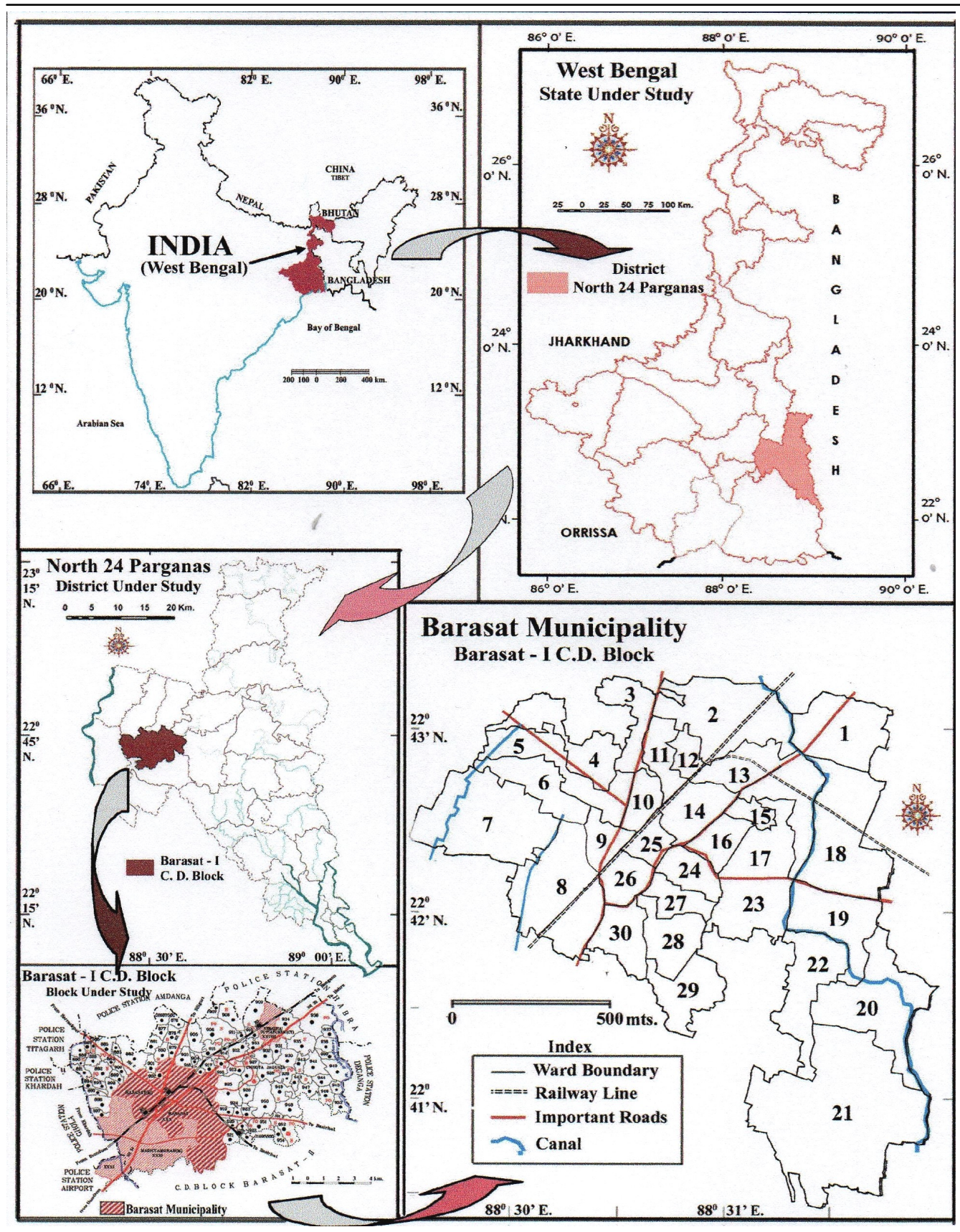

Fig. 1 - Locational Map of the Study Area 
Barasat town. The railway company has decided to develop Barasat station as a super model station, for which work has already started. There is a proposal of new bypass way along Barasat to Roychowk which connects North 24 Parganas district with South 24 Parganas district. Also the proposals of development and widening of National Highways are in existence.

Along with these development works Barasat Municipality has also taken the responsibility of development of various types of works within this town like slum development works, municipal infrastructure development works etc. and many other proposals have been submitted or about to be submitted for various govt. grants for infrastructural and social developments of Barasat municipal area. One of such type of proposal scheme is development of drainage net work ithin Barasat municipal area under JNNURM Programme.

The main objectives of this study are follows:

- To analyse the spatial distribution of socio-economic facilities for the people at micro level,

- $\quad$ To identify the leading factors of socio-economic disparities and

- To examine the magnitude of inter-ward disparities of the levels of socio-economic development in Barasat city.

\section{Materials and Methods}

The study is based on the primary data collected through the intensive field survey in several wards of Barasat Municipality.

The primary information is supplemented with secondary data whenever needed. To estimate a quantitative weight of a variable (i.e. number of primary school per 1000 population) total population of each ward as per Census of India, 2001 has been projected to 2010 during field investigation.

\section{Sample design and data collection}

In order to access the unequal resource distribution leading to the variation in development among core area, intermediate area and peripheral part of the city, the samples have been selected from each part of the wards. All thirty wards have been selected for purposive sampling. The information regarding number of selected socio-economic and facility-utility services has been collected non-partially, i.e. total number of concerned facility was ensured through field investigation. The entire field survey was conducted during March-June, 2010 and collected data have been analysed.

\section{Adoption of statistical techniques}

For the purpose of the present study both qualitative and quantitative methods have been adopted. However, in quantitative analysis both simple and standard statistical techniques have been used to infer the facts.

- $\quad$ Availability of infrastructure facility per unit population has been estimated in terms of actual number of facility per 1000 of projected population in 2010.

- $\quad$ Population for 2010 has been projected using simple arithmetic progression techniques.

- Accessibility of each facility in terms of nature of distribution per unit area has been measured using Mathur's method of Mean Spacing which is as follows: 


$$
D=1.0746 \sqrt{\mathrm{A} / \mathrm{N}}
$$

Where, $\mathrm{D}$ denotes theoretical distance between the facilities in a hexagonal pattern of area, $\mathrm{A}$ denotes area of the ward and $\mathrm{N}$ denotes the number of facility at that ward.

- In order to prove the internal reliability of the model used, the author has gone through

Cronbach's Alpha Test of Reliability. Applying this test specifies whether the items pertaining to each dimension are internally consistent and whether they can be used to measure the same construct or dimension of service quality.

- Levels of development have been estimated after constructing a composite index based on selected physical indicators.

Certain weights have been assigned to each indicator based on their value judgment to arrive at a meaningful and comparable composite index of development. For this purpose, Factor Analysis has been used to derive the factor loading or coefficient of each variable.

The factor loading of each variable has been multiplied by the corresponding standardized value to obtain their factor score.

Finally, the factor score of each variable has been added together to estimate the index of development of each unit of study or sampled ward of the city.

The statistical model which has been used may be expressed as:

$$
P_{1}=\sum a_{j 1} X Z_{j} \text { or } P 1=a_{11} \cdot Z_{1}+a_{21} \cdot Z_{2} a_{11}+\ldots \ldots \ldots a_{n 1} \cdot Z_{n}
$$

where, $\mathrm{P}_{1}$ denotes composite index of development of a unit study as first factor denotes the factor loading of the $j^{\text {th }}$ variable and 1 indicate the factor number, i.e. first factor - vector of factor loadings. $Z_{j}$ denotes standardized value of the $j^{\text {th }}$ variable, which is expressed as:

$$
Z_{j}=\frac{X_{j}-X_{m}}{\delta_{j}}
$$

where, $X_{j}$ denotes original value of $j^{\text {th }}$ variable, $X m$ denotes the mean of of $j^{\text {th }}$ variable and $\delta_{j}$ denotes the standard deviation of of $j^{\text {th }}$ variable.

\section{Findings and Analysis}

Availability of and accessibility to urban facilities in Barasat City

The problem of unequal distribution of facilities across the region is a common phenomenon in India. Such a problem leads to emergence of regional disparities in socio-economic development. The present study is an attempt to highlight the unequal distribution of socioeconomic facilities through the analysis of availability per unit of population and per unit of areal extension (mean spacing) of the different wards of the study area.

Education Facility is one of the significant determinants of social well-being, welfare as well as human development. Among the educational facilities, highest coefficient of variability of 388.96 has been accounted for colleges in Barasat city (Annexure-Table 2). However, among 
the education facilities, least coefficient of variation, i.e. C.V. = 100 has been computed in the distribution of school.

Highest availability of schools (X1) i.e. 4.38 followed by colleges (X2), i.e.0.17 per 1000 of population have been found in ward no. 24 and 25 respectively (Table no. 1.1). While lowest availability of 0.10 (X1) followed by 0.11 (X2) in ward no. 5 and 9 respectively. However, in area perspective analysis also, a similar figure is depicted in the distribution of school. Highest and lowest mean spacing of $0.95 \mathrm{~km}$. and $0.12 \mathrm{~km}$. has been recorded in ward no. 21 and 24 respectively (Annexure - Table 1). It reveals that in ward no. 24, schools are much closely spaced ensuring its better accessibility to the inhabitants than in other wards, while the inverse figure is found in ward no. 21. The colleges are located as far as $0.63 \mathrm{~km}$. apart from each other in ward no. 9 while as near as $0.46 \mathrm{~km}$ in ward no. 25. Further, Annexure table 2 reveals that the highest availability of college facility per 1000 population has been recorded in ward no. $9(0.11)$ and ward no. $25(0.17)$ while twenty eight wards are not having this facility. It comes out from the above assessment that better availability and accessibility of education facilities have been recorded in ward no. 24 and 25 (core part)

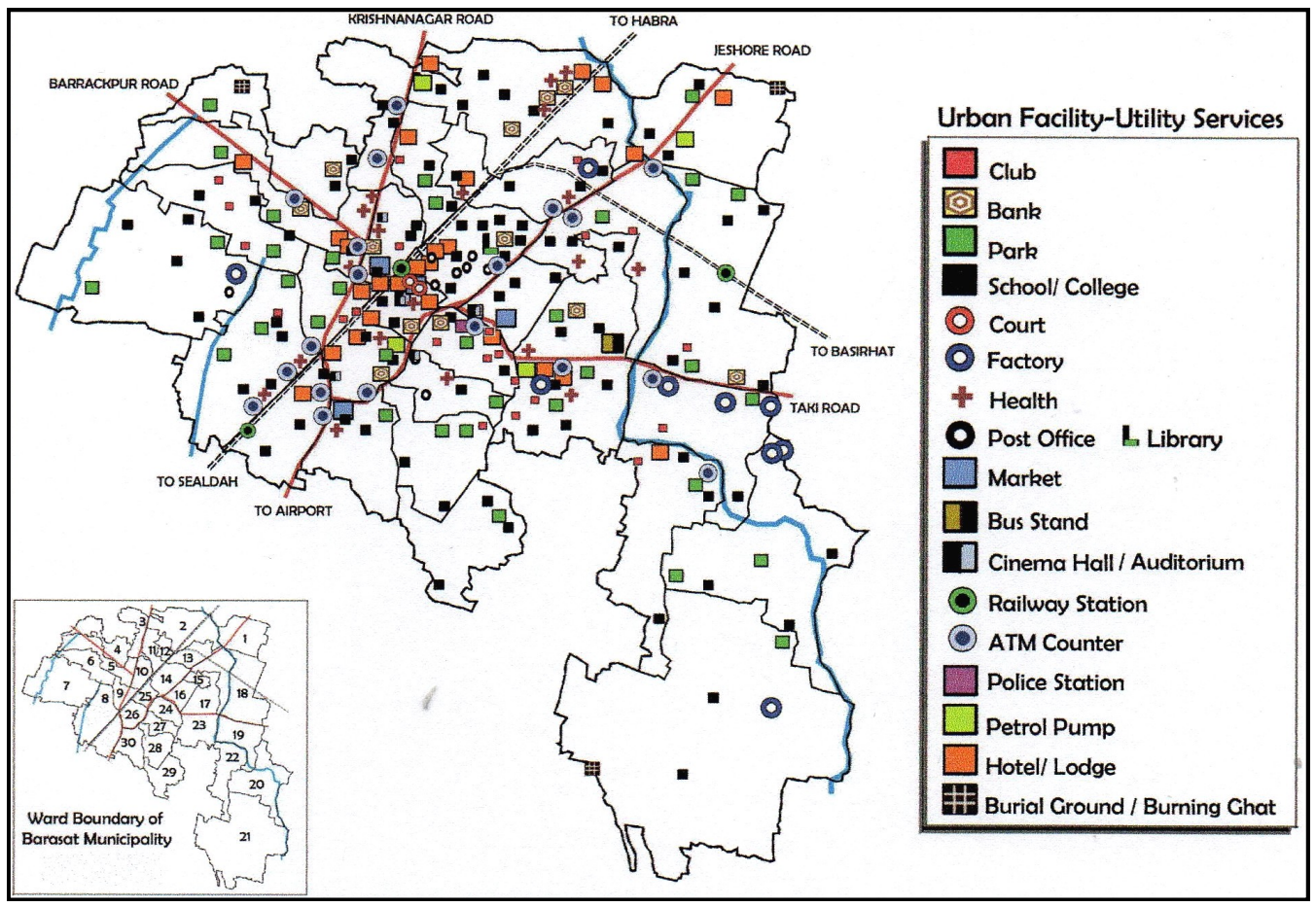

Fig. 2 - Distribution of Different Urban Facility-Utility Services in Barasat Municipality

Health Facility. The provision of availability and accessibility to health services can ensure better health condition of the inhabitants. It is another important indicator of human development. Among three selected health facilities, i.e. hospital (X3) and nursing home (X4), the availability of nursing homes (X4) per unit of population is much consistent (C.V. = 143.64). ). Out of 30 wards in Barasat Municipality, $3(10 \%)$ are having hospital facility and fourteen $(47 \%)$ are having nursing home facility. Ward no. 24 and 26 are better off in 
availability of (X3 and $\mathrm{X} 4)$ health facilities. However the analysis of mean spacing reveals better accessibility to health facility found in ward no. $10(0.48 \mathrm{~km}$.) for X3 and ward no. $24(0.30 \mathrm{~km}$.) for X4. It is evident from the analysis that, accessibility to health facility is better and it is more number in the core area of Barasat Municipality.

Financial Facility. This is an important indicator of economic development. The analysis reveals disparity in the availability of and accessibility to banking facility to the people of Barasat Municipality. Among 30 wards, banking facility (X5) is available in 14 wards (47\%). In case of availability per 1000 of population, ward no. $2(2.94)$ is in better position followed by ward no. $25(0.85)$, while in case of accessibility least mean spacing is found in ward no. $24(0.20 \mathrm{~km})$ since banks are located centrally. In case of availability of Factory (X6) and ATM counters (X7), it has been found that the central position of Barasat city which has Barasat Rail Station is having highest concentration of such facilities. It is evident from the above analysis that central portion of city is having good financial facility than other wards.

Another financial indicator for socio-economic development is market (X8). Besides the place of selling and purchasing of goods, it is the meeting place of people who exchange their social, cultural and political ideas leading to socio-cultural transformation of the society. Table 2 of annexure reveals high degree of variability $(C . V .=272.22)$ in its availability among the 30 wards of Barasat Municipality. Among the wards, ward no. 16 has been recorded to be in a better position of market availability of 0.16 per 1000 population. However, Table no. 4 reveals that accessibility of market is much better in ward no. 25, where markets are located at an average spacing of as lowest as $0.46 \mathrm{~km}$. as against $0.87 \mathrm{~km}$. mean spacing in ward no. 30 .

Communication and Transport Facility. Rail Station and Bus Stand were taken into accounts in this group. Actually, rail station is a crucial pull factor for the concentration of population in the urban area. The presence of rail station within the vicinity minimizes the time as well as it helps to connect the area with other parts of the district. Three rail stations have been located in the Barasat Municipality at ward no. 8, 14 and 18. Least mean spacing has been found in ward no. $14(0.64 \mathrm{~km}$.). Barasat town it well connected with roads to Kolkata, North Bengal, Bangladesh and other towns of West Bengal. The two National Highways (NH 34 \& NH 35) and one State Highway (SH 2) run through Barasat town, Barasat is also well connected by railway with Sealdah, Bongaon and Basirhat. Chanpadali Bus terminal or Titumir Central Bus Terminal is the main bus terminal in Barasat which provides with services to Kolkata and other parts of the district as well as the part of the state located in ward no. 17.

Other Facilities. Police station, library, cinema hall, park, hotel and lodge, petrol pump and burial ground and burning ghat etc. are the very important facilities for the urban people. Park (C.V. $=102.04)$ followed by hotels (C.V. $=180.98)$ are showing least amount of variability among other facilities (Annexure-Table 2). In case of accessibility, ward no. $11(0.35 \mathrm{~km}$.) and ward no. $25(0.16 \mathrm{~km}$.$) are having the least mean spacing in public urinals (X14) and hotels (X17)$ respectively.

\section{Reliability statistics}

In order to prove the internal reliability of the model used, the author has gone through Cronbach's Alpha Test of Reliability. Applying this test specifies whether the items pertaining to each dimension are internally consistent and whether they can be used to measure the same construct or dimension of service quality. According to Nunnaly (1978) Cronbach's Alpha should be 0.700 or above. But in some of the studies, 0.600 also considered acceptable (Gerrard et al. 2006, Kenova and Jonasson 2006). Table no. 1 indicates that the some of the 
Cronbach's Alpha values of accuracy were (.666 for $X_{6}, .661$ for $X_{10}$ and .614 for $X_{18}$ ) less than 0.700 . Therefore, these items were eliminated from the factor analysis. However, if Cronbach's Alpha value of all items were acceptable, it means that the present data are suitable for factor analysis.

Reliability Statistics Using Cronbach's Alpha

Table 1

\begin{tabular}{|c|c|c|c|}
\hline $\begin{array}{c}\text { Description of } \\
\text { Variables }\end{array}$ & $\begin{array}{c}\text { Cronbach's } \\
\text { Alpha }\end{array}$ & $\begin{array}{c}\text { Description of } \\
\text { Variables }\end{array}$ & $\begin{array}{c}\text { Cronbach's } \\
\text { Alpha }\end{array}$ \\
\hline No. of Schools/ '000 Population $\left(\mathbf{X}_{1}\right)$ & .786 & No. of Library/ '000 Population $\left(\mathbf{X}_{11}\right)$ & .755 \\
\hline No. of Colleges/ '000 Population ( $\left.\mathbf{X}_{2}\right)$ & .725 & No. of Railway Stations/ '000 Population $\left(\mathbf{X}_{12}\right)$ & .856 \\
\hline No. of Hospitals/ '000 Population ( $\left.\mathbf{X}_{3}\right)$ & .775 & $\begin{array}{l}\text { No. of Bus Stand/ '000 } \\
\text { Population }\left(\mathbf{X}_{\mathbf{1 3}}\right)\end{array}$ & .761 \\
\hline $\begin{array}{l}\text { No. of Nursing Homes / '000 } \\
\text { Population }\left(\mathbf{X}_{\mathbf{A}}\right)\end{array}$ & .703 & No. of Parks/ '000 Population $\left(\mathbf{X}_{14}\right)$ & .750 \\
\hline No. of Banks/ '000 Population $\left(\mathbf{X}_{5}\right)$ & .822 & $\begin{array}{l}\text { No. of Cinema hall, Auditorium / '000 } \\
\text { Population }\left(\mathbf{X}_{15}\right)\end{array}$ & .713 \\
\hline No. of Factories/ 000 Population $\left(X_{6}\right)$ & .666 & $\begin{array}{l}\text { No. of Petrol Pump / '000 } \\
\text { Population }\left(\mathbf{X}_{16}\right)\end{array}$ & .730 \\
\hline $\begin{array}{l}\text { No. of ATM Counters / '000 } \\
\text { Population }\left(\mathbf{X}_{7}\right)\end{array}$ & .740 & $\begin{array}{l}\text { No. of Hotel, Lodges/ '000 } \\
\text { Population }\left(\boldsymbol{X}_{17}\right)\end{array}$ & .888 \\
\hline No. of Markets/ '000 Population $\left(\mathbf{X}_{8}\right)$ & .728 & $\begin{array}{l}\text { No. of Burial Grounds/ } 000 \\
\text { Population }\left(X_{18}\right)\end{array}$ & .614 \\
\hline $\begin{array}{l}\text { No. of Police Stations / '000 } \\
\text { Population }\left(\mathbf{X}_{9}\right)\end{array}$ & .759 & No. of Clubs / '000 Population $\left(\mathbf{X}_{19}\right)$ & .765 \\
\hline No. of Courts/ 000 Population $\left(X_{10}\right)$ & .661 & & \\
\hline
\end{tabular}

Source: Computed by the Author

\section{Levels of socio-economic development}

An unequal and irrational distribution of facilities in urban centres without considering the size of the population and extent of area cause regional disparities in terms of socio-economic development. It is the characteristic of developing economy.

Development is a multi-faceted phenomenon which a society or a region achieves. As a spatial phenomenon, development of a region is explained in two ways, firstly as the state of change in the distribution of parameters between given points of time, and secondly, the state of their existing distribution. The state of imbalance of development inspires regional planners for formulating the diagnostic plan to achieve balanced regional development.

In the analysis, the development index of each ward has been estimated as a composite of factor score of each variable with factor coefficient more than 0.50 . Using the Principal Component Analysis, the factor coefficients have been arranged into six factors (i.e. Factor I, Factor II, Factor III, Factor IV, Factor V and Factor VI) in which first factor reveals 21.89 per cent variance, while second, third, fourth, fifth and sixth reveal 19.15 per cent, 13.32 per cent, 11.45 per cent, 9.57 per cent and 8.06 per cent respectively. Therefore, all the six factors cumulatively reveal 82.45 per cent of variance (Table 1). Among them, the first three have been taken into consideration for estimation of development, as these three factors combine to reveal 54.37 per cent variance. More than 0.5 value of factor coefficient have taken into consideration for determining the development index. Variables $X_{5}, X_{7}, X_{12}, X_{13}, X_{16}$ and $X_{17}$ showing factor coefficient more than 0.50 in Factor I have been multiplied by standardized 
value of the respective variable to derive their factor score and finally to estimate the composite index of development (Table 1). Likewise, variables $X_{1}, X_{2}$ and $X_{8}$ with their factor coefficient more than 0.50 have been identified in Factor II. Again, for Factor III, $X_{3}$ and $X_{9}$ are considered as they have coefficient value of more than 0.50 . But no single variable shows factor coefficient more than 0.50 in Factor IV, though variables $X_{11}$ and $X_{15}$ show factor coefficient more than 0.50 in Factor IV which reveals only 11.45 per cent variance and has not been included in the estimation of development index. Subsequently out of 16 variables, 14 variables are observed as significantly responsible and 12 variables have been taken to examine the spatial variation of socio-economic development in Barasat city.

Table 2

Factor Loading of Variables, Barasat City, 2010

\begin{tabular}{|c|c|c|c|}
\hline \multirow{2}{*}{ Variables and Definitions } & \multicolumn{3}{|c|}{ Component } \\
\hline & Factor I & Factor II & Factor III \\
\hline No. of Schools/ 000 Population $\left(\mathbf{X}_{1}\right)$ & .405 & .812 & .403 \\
\hline No. of Colleges/ '000 Population $\left(X_{2}\right)$ & .099 & .750 & -.110 \\
\hline No. of Hospitals/ '000 Population $\left(X_{3}\right)$ & .075 & -.019 & .713 \\
\hline No. of Nursing Homes / '000 Population $\left(\mathbf{X}_{\mathbf{4}}\right)$ & .392 & -.018 & .839 \\
\hline No. of Banks/' 000 Population $\left(\mathbf{X}_{5}\right)$ & .923 & .104 & .035 \\
\hline No. of ATM Counters / '000 Population $\left(X_{7}\right)$ & .708 & .275 & .107 \\
\hline No, of Markets/'000 Population $\left(\mathbf{X}_{8}\right)$ & -.012 & .889 & .036 \\
\hline No, of Police Stations / '000 Population $\left(X_{0}\right)$ & -.195 & -.033 & .902 \\
\hline No. of Library/ '000 Population $\left(\mathbf{X}_{11}\right)$ & .035 & .095 & .009 \\
\hline No. of Railway Stations/ 000 Population $\left(\mathbf{X}_{12}\right)$ & .940 & -.134 & .047 \\
\hline No. of Bus Stand/ '000 Population $\left(X_{13}\right)$ & .726 & .036 & -.011 \\
\hline No. of Parks/ '000 Population $\left(\boldsymbol{X}_{14}\right)$ & -.048 & -.264 & .265 \\
\hline No. of Cinema hall, Auditorium / '000 Population ( $\left.X_{15}\right)$ & .079 & .428 & .007 \\
\hline No. of Petrol Pump / 000 Population $\left(X_{16}\right)$. & .930 & -.183 & .154 \\
\hline No. of Hotel, Lodges/ 000 Population $\left(X_{17}\right)$ & .888 & .308 & .098 \\
\hline No. of Clubs / '000 Population $\left(X_{19}\right)$ & .029 & .082 & -.146 \\
\hline$\%$ of Variance & 21.899 & 19.150 & 13.324 \\
\hline Cumulative $\%$ of Variance & 21.899 & 41048 & 54.372 \\
\hline
\end{tabular}

Source: Computed by the Author.

*Note. Extraction Method - Principal component analysis, Rotation Method.

\section{Levels of development - Factor I (commercial and transport facility)}

On the basis of composite development index of factor I, the sample wards have been arranged into three levels in order to study the inter-ward disparities of development in socioeconomic amenities ((Annexure-Table 3a)). Out of 30 wards, 7 wards $(23 \%)$ with development index more than 1.00 fall in high level of development. These wards are located almost at the core area of the city. Due to the old built up area, these wards posses essential amenities like, education, health, communication, drinking water, marketing and easy transport facility. 
Levels of Development - Factor I, (Commercial and Transport Facility), Barasat City, 2010

\begin{tabular}{|cccc|}
\hline $\begin{array}{c}\text { Level of } \\
\text { Development }\end{array}$ & Indices & $\begin{array}{c}\text { Number of } \\
\text { Wards }\end{array}$ & Identity of Wards \\
\hline High & Above 1.00 & $07(23 \%)$ & Ward no. 2, 25, 14, 8, 17, 23 and 18 \\
Medium & 1.00 to -1.00 & $06(20 \%)$ & Ward no. 26, 3, 10, 13, 1 and 9 \\
Low & Below -1.00 & $17(57 \%)$ & Ward no. 30, 24, 5,19,27, 12, 7, 28, 21, 22, \\
\hline
\end{tabular}

Source: Computed by the Author from annexure - Table 3

Six wards (i.e. ward no. 26, 3, 10, 13, 1 and 9) with development index ranging 1.00 to -1.00 come under medium level of development. Further, table 3 reveals that with development index less than -1.00 seventeen wards $(57 \%)$ are under low level of development in the city. All these wards are located in buffer and peripheral parts of Barasat city. People are living in these wards with difficulties in financial facilities and transport. As a result, the quality of life and level of living of people of these areas are deteriorating gradually.

$$
\text { Levels of development - Factor II (education facility) }
$$

Variables $\mathrm{X} 1, \mathrm{X} 2$ and $\mathrm{X} 8$ in factor II altogether explain the levels of development of education (schools and colleges) in the city (Annexure-Table No. 3). Only 6 wards (20\%) i.e. ward no. 16, $5,11,22,3$ and 10 with development index more than 1.00 have been categorized under high level of development. Out of six wards in this category, three are located in the core while ward no 5 and 3 are located in the outer part.

Fifteen wards i.e. ward no 25, 29, 30, 27, 19, 9, 26, 4, 24, 7, 20, 12, 13, 14 and 1 have been found in the medium level of health development in the city. The wards under medium development have scored index ranging from 1.00 to -1.00 .

Further, a majority of wards (i.e. no of wards 9) have been found with development index of less than -1.00 which has been considered to be under the low level of health infrastructure facility in the city. These wards are located in the city in scattered form.

Levels of Development - Factor II (Education and Market),

Table 4 Barasat City, 2010

\begin{tabular}{|cccc|}
\hline $\begin{array}{c}\text { Level of } \\
\text { Development }\end{array}$ & Indices & $\begin{array}{c}\text { Number of } \\
\text { Wards }\end{array}$ & Identity of Wards \\
\hline High & Above 1.00 & $06(20 \%)$ & Ward no. 16, 5, 11, 22, 3 and 10 \\
Medium & 1.00 to -1.00 & $15(50 \%)$ & Ward no. 25, 29, 30, 27, 19, 9, 26, 4, 24, 7, 20, 12, \\
Low & Below -1.00 & $09(30 \%)$ & Ward no. 21, 2, 28, 23, 6, 8, 18, 15 and 17 \\
\hline
\end{tabular}

Source: Computed by the Author from annexure - Table 3

Levels of development - Factor III (health and administrative)

On the basis of factor III, variables $\mathrm{X} 3, \mathrm{X} 4$ and $\mathrm{X} 8$ have been marked as important factors for the development in socioeconomic condition of Barasat city. Six wards with development index 
more than 1.00 (Annexure-Table No. 3) fall under higher degree of development. These are ward no. 24, 26, 10, 5, 2 and 23. Except ward no. 2 and 5, rest of the area lies in the administrative part of the city. Due to location of C.B.D. and being the district headquarter, Barasat city provides some good health facilities to the society.

Table 5

Levels of Development - Factor III, (Health and Administrative facility), Barasat City, 2010

\begin{tabular}{|cccc|}
\hline $\begin{array}{c}\text { Level of } \\
\text { Development }\end{array}$ & Indices & Number of Wards & Identity of Wards \\
\hline High & Above 1.00 & $06(20 \%)$ & Ward no. 24, 26, 10, 5, 2 and 23 \\
Medium & 1.00 to -1.00 & $17(57 \%)$ & Ward no. 13, 16, 14, 17, 8, 18, 15, 30, 1, 3, 4, 6, 7, \\
& & & $9,11,12$ and 19 \\
Low & Below -1.00 & $07(23 \%)$ & Ward No. 20, 21, 22, 25, \\
27.28 and 29
\end{tabular}

Source: Computed by the Author from annexure - Table 3

Seventeen wards (i.e. ward no. 13, 16, 14, 17, 8, 18, 15, 30, 1, 3, 4, 6, 7, 9, 11, 12 and 19) with development indices ranging 1.00 to -1.00 come under the medium level of development. Again seven wards $(23 \%)$ out of thirty wards have been foundin the low level of development index having value less than -1.00 . These wards are located basically in the outer part. It has been found that market, road and hotel are not good in number in those areas.

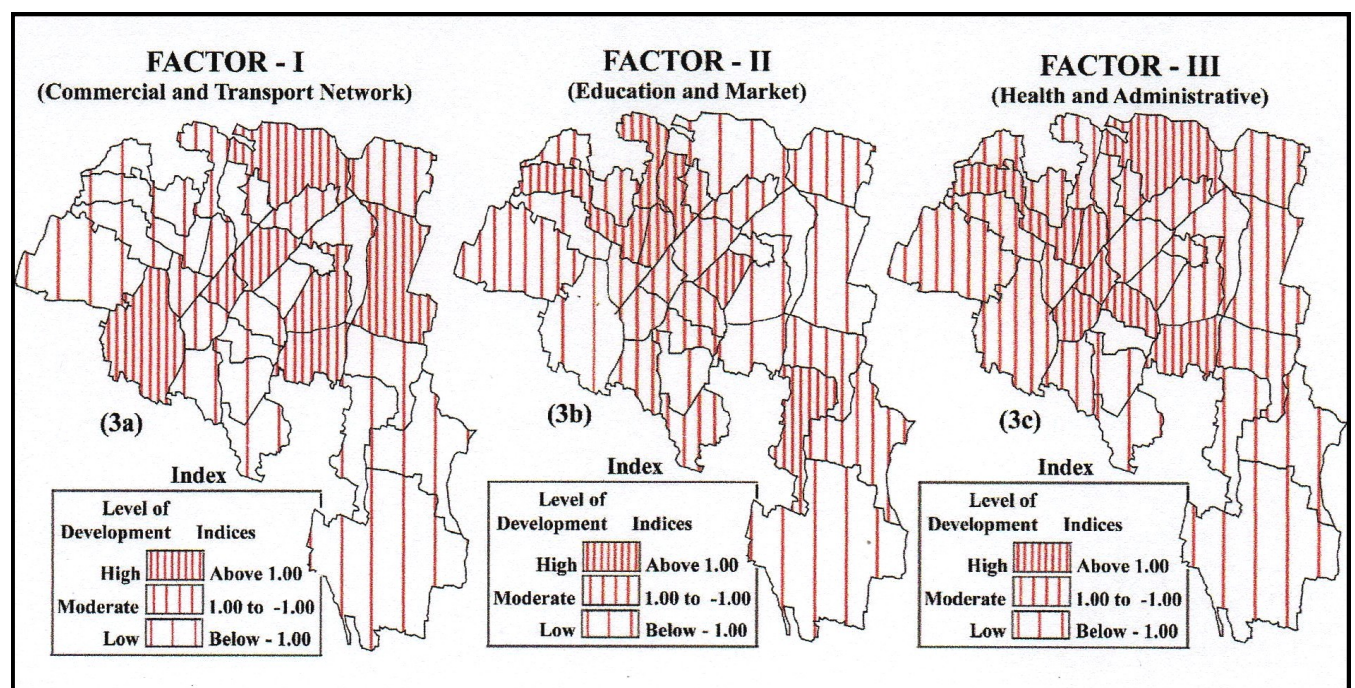

Fig. 3 - The levels of Development for Factor - I, Factor - II, Factor - III

\section{Conclusion}

The foregoing analysis based on the field survey infers to the inter-ward disparities in socioeconomic development consequent upon the irrational as well as unequal distribution of amenities and facilities. It has come out from the study that, the peripheral area of the city is lagging behind in socio-economic amenities resulting into low level of development. The low 
level of development in the wards is mainly due to the allocation of facilities without corresponding to the population size, poor condition of roads and finally negligence from the city government side to allocate resources. Another important finding from the empirical observation is that, government medical facility is very poorly available to people of Burdwan city. To wipeout this problem of existing inter-ward disparities in the level of socio-economic development from Class I Indian cities like Barasat city, a diagnostic plan should be formulated to provide and locate resources according to population size.

Subsequently, the balanced development would be achieved and social justice to the people would be ensured; consequently, human well-being and welfare should be the desired result of relentless and selfless efforts made by the people, the government and the NGOs.

\section{ANNEXURE}

Table 1

\section{Accessibility-Mean Spacing (Per Unit Area) of Facilities, Barasat Municipality, 2010}

\begin{tabular}{|c|c|c|c|c|c|c|c|c|c|c|c|c|c|c|c|c|c|c|c|}
\hline Vards No. & $X_{1}$ & $\bar{X}_{2}$ & $X_{3}$ & $X_{4}$ & $\bar{X}_{5}$ & $X_{6}$ & $\bar{X}$ & $\bar{X}_{8}$ & $X_{9}$ & $X_{10}$ & $X_{11}$ & $X_{12}$ & $\overline{X_{13}}$ & $\overline{X_{14}}$ & $\overline{X_{15}}$ & $\overline{X_{16}}$ & $\overline{X_{17}}$ & 18 & 419 \\
\hline & 49 & ח0 & 00 & 10 & 00 & 0.00 & 00 & 50 & .00 & 00 & .00 & 2.00 & 0 & .85 & 0.00 & .85 & 8.85 & 85 & 60 \\
\hline & 0.46 & 00 & 0.00 & 1.03 & .46 & 0.00 & 00 & .00 & 0.00 & 0.00 & 0.00 & 0.00 & 0.00 & 0.00 & 0.00 & 1.03 & 0.51 & 0. & 0.00 \\
\hline & 0.43 & 0 & 00 & 00 & 00 & 0.00 & 43 & 00 & 0.00 & .00 & 00 & 0.00 & .00 & .00 & 0.00 & .00 & .00 & 0.00 & 1.30 \\
\hline & 0.53 & 00 & .00 & 00 & 4 & 0.00 & 10 & 10 & 0.00 & 0.00 & .00 & 0.00 & .00 & 0.74 & 0.00 & .00 & 0.00 & 0.74 & .00 \\
\hline & 0.77 & 00 & 77 & 55 & 77 & 0.00 & .55 & .00 & 0.00 & .00 & .00 & 0.00 & .00 & .55 & 0.00 & .00 & 00 & 0.00 & .00 \\
\hline & 0.47 & 00 & .00 & 00 & 0 & 0.00 & 30 & .00 & 0.00 & .00 & 0.00 & 0.00 & 1.00 & 0.67 & 0.00 & .00 & 0.00 & 0.00 & 39 \\
\hline & 0 & 0 & 0.00 & 00 & 80 & 1.14 & 14 & .00 & 0.00 & 0.00 & 00 & 0.00 & 00 & 0.80 & 0.00 & .00 & 0.00 & .00 & 1.00 \\
\hline & 0.35 & 00 & 0.00 & 0.85 & 0 & 0.00 & 0.38 & 00 & 0.00 & 1.00 & 0.00 & 0.85 & 1.00 & 0.49 & 0.00 & .00 & 0.00 & 0.00 & 185 \\
\hline & 10 & 63 & 00 & 00 & 00 & 0.00 & 44 & .00 & 0.00 & 0.00 & .63 & 0.00 & 0.00 & 0.44 & 0.00 & 0.00 & 0.36 & 0.00 & 0.00 \\
\hline & 0.24 & .00 & 0.48 & 0.34 & 34 & 0.48 & .00 & .48 & 0.00 & .00 & .48 & 0.00 & 1.00 & 0.48 & 0.0 & .00 & .20 & 0.00 & .00 \\
\hline & 0.22 & 00 & 00 & 30 & 00 & 0.00 & 00 & 1.00 & 0.00 & 0.00 & .00 & 0.00 & .00 & 0.35 & 0.00 & .00 & 0.35 & 0.00 & .28 \\
\hline & 0.21 & 0.00 & 0.00 & 00 & 55 & 0.00 & 0.55 & .00 & 0.0 & 0.00 & 0.00 & 0.0 & 0.00 & 0. & 0. & 0.00 & 0. & 0.00 & 0.39 \\
\hline & 33 & בח & 00 & 54 & 0.94 & 0.94 & 54 & 00 & 0.0 & 0.00 & 0 & 0.00 & 00 & 0.94 & 0.8 & . & 0.00 & 0.00 & .54 \\
\hline 14 & 0.16 & 0.00 & 0.00 & 0.45 & 64 & 0.00 & 0.64 & 0.00 & 0.00 & 0.00 & 0.37 & 0.64 & 0.00 & 0.45 & 0.00 & 0.00 & 0.24 & 0.00 & 0.00 \\
\hline 15 & 0. & 0.00 & 0.00 & 0.37 & 00 & 0.00 & 0.00 & 0.00 & 0.00 & 0.00 & 0.00 & 0.00 & 0.00 & 0.00 & 0.00 & 0.00 & 0.00 & 0.00 & 0.00 \\
\hline & 0.24 & 00 & 0.00 & 0.37 & 1.00 & 0.37 & 0.00 & 0.53 & 0.00 & 0.00 & 0.00 & 0.00 & 0.00 & 0.00 & 0.53 & 0.00 & 0.53 & 0.00 & 0.00 \\
\hline & 0.25 & 0 & 0.00 & 70 & 49 & 0.00 & .00 & 0.00 & 0.00 & 0.00 & 0.00 & 0.00 & 0.70 & 0.49 & 0.00 & 0.00 & 0.00 & 0.70 & 0.00 \\
\hline & 0.30 & 0.00 & 0.00 & 1.10 & 1.10 & 0.00 & 00 & 0.00 & 0.00 & 0.00 & 0.00 & 1.10 & 0.00 & 0.55 & 0.00 & .00 & 0.00 & 10 & 10 \\
\hline 19 & 0.30 & 0.00 & 0.00 & 0.00 & 0.57 & 0.46 & 0.80 & 0.00 & 0.00 & 0.00 & 0.00 & 0.00 & 0.00 & 0.57 & 0.00 & 0.00 & 0.00 & 0.00 & 0.80 \\
\hline & 0.42 & 0.00 & 0.00 & 0.00 & 0.00 & 0.72 & 0.00 & 0.00 & 0.00 & 0.00 & 0.00 & 0.00 & 0.00 & 0.72 & 0.00 & 0.00 & 0.00 & 0.00 & 0.00 \\
\hline & 0.95 & 0.00 & 0.00 & 0.00 & 0.00 & 1.64 & 1.64 & 0.00 & 0.00 & 0.00 & 0.00 & 0.00 & 0.00 & 1.16 & 0.00 & 0.00 & 0.00 & 1.64 & 0.00 \\
\hline Nalu NO. LL & 0.41 & 0.00 & 0.00 & 0.00 & 0.00 & 0.00 & 0.00 & 0.00 & 0.00 & 0.00 & 0.00 & 0.00 & 0.00 & 0.82 & 0.00 & 0.00 & 0.58 & 0.00 & 0.00 \\
\hline & 0.21 & 00 & .00 & 0.53 & 00 & 075 & 0.00 & 0.00 & 0.0 & 0.00 & 0.00 & 0.00 & 0.00 & 0. & 0 & 0.10 & 0.43 & 0. & 0.0 \\
\hline 24 & 0.12 & 0.00 & 0.00 & 0.30 & 0.00 & 0.00 & 0.52 & 0.00 & 0.52 & 0.00 & 0.00 & 0.00 & 0.00 & 0.52 & 0.00 & 0.00 & 0.00 & 0.00 & 0.00 \\
\hline 20 & 0.15 & 0.46 & 0.00 & 0.00 & 0.20 & 0.00 & 0.23 & 0.46 & 0.00 & 0.32 & 0.00 & 0.00 & 0.00 & 0.00 & 0.32 & 0.00 & 0.16 & 0.00 & 0.23 \\
\hline 20 & 0.26 & 0.00 & 0.64 & 0.64 & 0.46 & 0.00 & 0.00 & 0.00 & 0.00 & 0.00 & 0.00 & 0.00 & 0.00 & 0.00 & 0.00 & 0.64 & 0.32 & 0.00 & 0.37 \\
\hline 27 & 0.26 & 0.00 & 0.00 & 0.00 & 0.00 & 0.00 & 0.36 & 0.00 & 0.00 & 0.00 & 0.00 & 0.00 & 0.00 & 0.52 & 0.00 & 0.00 & 0.00 & 0.00 & 0.52 \\
\hline & 0.41 & 0.00 & 00 & 10 & 0 & 0.00 & 0 & 0.00 & 0.00 & 0.00 & 0.00 & 0.00 & 0.00 & 0.50 & 0.00 & 0.00 & 0.00 & 0.00 & 0.00 \\
\hline & U.s5 & 00 & 0.00 & 0.00 & 1.00 & 0.00 & 0.00 & 0.00 & 0.00 & 0.00 & 0.00 & 0.00 & 0.00 & 0.70 & 0.00 & 0.00 & 0.00 & 0.00 & 0.00 \\
\hline $\operatorname{ard}$ No. 30 & 0.26 & 0.00 & 0.00 & 0.87 & 0.00 & 0.00 & 0.50 & 0.87 & 0.00 & 0.00 & 0.87 & 0.00 & 000 & 0.62 & $0 \cap 0$ & $\cap \cap 0$ & $\cap 62$ & $\cap \cap 0$ & $0 \cap 0$ \\
\hline
\end{tabular}

Source: Computed by the Author 
Analysis of Micro Level Disparities in Urban Facility-Utility Services:

a Study on Barasat City, West Bengal, India

\section{ANNEXURE}

Table 2

Availability of Facility (Per Unit Per '000 population), Barasat Municipality, 2010

\begin{tabular}{|c|c|c|c|c|c|c|c|c|c|c|c|c|c|c|c|c|c|c|c|}
\hline $\begin{array}{l}\text { Wards } \\
\text { No. }\end{array}$ & $x_{1}$ & $X_{2}$ & $x_{3}$ & $X_{4}$ & $X_{5}$ & $X_{6}$ & $X_{7}$ & $X_{8}$ & $X_{g}$ & $X_{10}$ & $X_{11}$ & $X_{12}$ & $X_{13}$ & $X_{14}$ & $X_{15}$ & $X_{16}$ & $X_{17}$ & $X_{18}$ & $X_{19}$ \\
\hline 1 & 0.42 & 0.00 & 0.00 & 0.00 & 0.00 & 0.00 & 0.00 & 0.00 & 0.00 & 0.00 & 0.00 & 0.00 & 0.00 & 0. & 0.00 & 0.14 & 11 & 14 & 0.28 \\
\hline 2 & 2.94 & 0.00 & 0.00 & 0.59 & 2.94 & 0.00 & 0.00 & 0.00 & 0.0 & 0.00 & 0.00 & .00 & & & 0.00 & 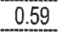 & & 0 & 0.00 \\
\hline 3 & 0.63 & 100 & 0.00 & 1.00 & 0.00 & & 063 & 000 & & & & 00 & & & 00 & & & 00 & 1.26 \\
\hline 4 & 0.30 & & & & & & & & & & & 00 & & & 0.00 & .00 & & 15 & 0.00 \\
\hline 5 & 0. & 0. & 0. & 20 & 0.10 & 0 & 0.20 & 0.00 & 0.00 & 0.00 & 0.00 & 0.00 & 0.00 & 0.20 & 0.00 & 0.00 & 0 & .00 & 0.00 \\
\hline 6 & 0.33 & 0.00 & 0.00 & 0.00 & 0.00 & 0 & 0.00 & 0.00 & 0.00 & 0.00 & 0.00 & 0.00 & 0.00 & 0.1 & 0.00 & 0.00 & & 0.00 & 0.49 \\
\hline 7 & 0.29 & 0.00 & 0.00 & 0.00 & 0.14 & 0.07 & 0.07 & 0.00 & 0.00 & 0.00 & 0.00 & 0.00 & 0.00 & 0.14 & 0.00 & 0.00 & & 00 & 0.00 \\
\hline 8 & 0.97 & 0.00 & 0.00 & 0.16 & 0.00 & 0.00 & 0.81 & 0.00 & 0.00 & 0.00 & 0.00 & 0.16 & 0.00 & 0.49 & 0.00 & 0.00 & 0.0 & 1.00 & 0.16 \\
\hline 9 & 0.33 & 0. & 0.00 & 0.00 & 0.00 & 0.0 & 0.22 & 0.00 & 0 & 0. & 0. & 0.00 & 0.00 & 0.22 & 0.00 & 00 & & 0 & 0.00 \\
\hline 10 & 0.46 & 0.00 & 0.1 & 0.2 & 0.23 & 0 & 0.00 & 0.11 & 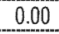 & 0.00 & 0.11 & 0.00 & .00 & & 00 & 00 & & 0 & 0.00 \\
\hline 11 & 0.5 & 0.00 & 0 & 0. & 0.0 & 0 & 0.00 & 0.00 & 0 & 0.00 & 0 & .00 & 00 & 0 & 0.00 & 1.00 & & o & 0.31 \\
\hline 12 & 0.5 & 0 & 0 & 0 & 0.07 & 0 & 0.07 & 0.00 & 0 & 00 & 0.0 & 0.00 & 00 & 0.0 & 0.00 & 0.00 & & 0.00 & 0.15 \\
\hline 13 & 0.99 & 0. & 0.0 & 0.37 & 0.12 & 0 & 0.37 & 0.00 & 0.0 & 0. & 0.0 & 0.00 & 0.00 & & 0.00 & 0.00 & 0.0 & 00 & 0.37 \\
\hline 14 & 2.60 & 0.0 & 0.00 & 0.32 & 0.16 & 0.0 & 0.16 & 0.00 & 0.00 & 0.00 & 0.49 & 0.16 & 0.00 & 0.32 & 0.00 & 0.00 & 1.1 & 0.00 & 0.00 \\
\hline 15 & 0.7 & & 0 & 0 & 0.00 & 0 & 0. & 0.00 & 0 & 0.00 & 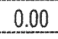 & 0.00 & 0.00 & 0.00 & 0.00 & 0.00 & 0.0 & 0.00 & 0.00 \\
\hline 16 & 0.92 & 0.00 & 0.00 & 0.37 & 0.00 & 0.37 & 0.00 & 0.18 & 0.00 & 0.00 & 0.00 & 0.00 & 0.00 & 0.00 & 0.18 & 0.00 & 0. & 0.00 & 0.00 \\
\hline 17 & 2.0 & 0.0 & 0.0 & 0.2 & 0.50 & 0. & 0.0 & 0.0 & 0 & 0. & 0 & 0.00 & 0 & 0.5 & 0.00 & 0.00 & 0.8 & 0.25 & 0.00 \\
\hline 18 & 2.09 & 0.0 & 0.0 & 0.16 & 0.16 & 0.0 & 0.00 & 0.00 & 0.0 & 0.00 & 0.00 & 0.16 & 0.00 & 0.6 & 0.00 & 0.00 & 0.00 & 0.00 & 0.16 \\
\hline 19 & 0.6 & & 0.00 & 0.00 & 0.1 & & 0. & 0.0 & 0 & 0. & 0 & 0.00 & 0.00 & 0.1 & 0.00 & 0.00 & 0.0 & 0.00 & 0.09 \\
\hline 20 & 0.7 & 0. & 0.0 & 0.0 & 0.00 & 0.2 & 0.0 & 0.00 & 0 & 0. & 0 & 0.00 & 0.00 & 0 & 0.00 & 0.00 & 0.0 & 0.00 & 0.00 \\
\hline 21 & & & & & 0.00 & & & & & & & 0.00 & & 0.2 & 0.0 & 0.00 & 0. & 0.12 & 0.00 \\
\hline 22 & 0 & 0.0 & 0. & 0. & 0.00 & 0. & 0.0 & 0.0 & 0. & 0. & 0 & 0.00 & 0 & 0 & 0.00 & 0.00 & 0.2 & 0.00 & 0.00 \\
\hline 23 & 3.75 & 0. & 0.0 & 0.5 & 0.00 & 0.2 & 0.0 & 0.00 & 0 & 0 & 0 & 0.00 & 0 & 0 & 0.00 & 0.29 & 0.8 & 0.29 & 0.00 \\
\hline 24 & $\begin{array}{r}4.38 \\
\end{array}$ & 0. & 0 & 0. & 0. & 0. & 0 & 0. & 0 & 0 & 0 & 0.00 & 0 & 0 & 0.00 & 0.00 & & 0 & 0.00 \\
\hline 25 & 1.5 & 0.1 & 0.0 & 0. & 0.84 & 0. & 0. & 0.17 & 0. & 0 & 0 & 0.00 & 0.00 & 0 & 0.34 & 0.00 & 1.3 & 0.00 & 0.67 \\
\hline 26 & 0.97 & 0.0 & 0. & 0 & 0.32 & & 0 & 0.00 & & & & 0.00 & 0.0 & 0 & 0.00 & 0.16 & 0.65 & 10 & 0.48 \\
\hline 27 & 0.32 & 0.00 & 0.0 & 0. & 0.00 & 0 & 0. & 0.0 & & & 0 & 0.00 & 0. & 0 & 0.00 & 0.00 & 0 & 0.00 & 0.08 \\
\hline 28 & 0.2 & 0.0 & 0.0 & 0.0 & 0.24 & 0.0 & 0.0 & 0.0 & 0. & 0 & 0. & 0.00 & 0 & 0.1 & 0.00 & 0.00 & 0.00 & 0.00 & 0.00 \\
\hline 29 & 0.6 & 0. & 0 & 0.0 & 0 & 0. & 0. & 0. & 0. & 0 & 0. & 0.00 & 0. & 0. & 0.00 & 0.00 & 0. & 0.00 & 0.00 \\
\hline 30 & 0.91 & 0.00 & 0.00 & 0.08 & 0.00 & 0.00 & 0.25 & 0.08 & 0.00 & 0.00 & 0.08 & 0.00 & 0.00 & 0.17 & 0.00 & 0.00 & 0.17 & 0.00 & 0.00 \\
\hline Mean & 1.07 & 0.01 & 0.01 & 0.1 & 0.21 & 0 & 0 & 0 & 0 & 0 & 0 & 0.02 & 0 & 0 & 0 & 0.04 & 0.28 & 0.03 & 0.15 \\
\hline $\begin{array}{c}\text { St. } \\
\text { Dev. }\end{array}$ & 1 & 0.0 & 0.0 & 0.21 & 0.5 & 0. & 0. & 0 & 0 & 0.00 & 0.00 & 0.05 & $0.0 \mathrm{~J}$ & 0.20 & 0.01 & 0.12 & 0.53 & 0.08 & 0.28 \\
\hline C.V. & 100.4 & 388.9 & 312.9 & 143.6 & 266.2 & 195.0 & 160.4 & 272.2 & 547.7 & 547.7 & 349.1 & 305.1 & 547.7 & 102.0 & 397.3 & 308.9 & 180.9 & 243.4 & 184.2 \\
\hline
\end{tabular}

Source: Computed by the Author 


\section{ANNEXURE}

Table 3

Factor Scoring of Variables (Factor Loading $>0.50$ ) and Index of Development, Barasat Municipality, 2010

\begin{tabular}{|c|c|c|c|c|c|c|c|c|c|c|c|c|c|c|c|}
\hline \multirow{2}{*}{$\begin{array}{c}\text { Wards } \\
\text { No. }\end{array}$} & \multicolumn{7}{|c|}{ Factor -1} & \multicolumn{4}{|c|}{ Factor - II } & \multicolumn{4}{|c|}{ Factor - III } \\
\hline & $X_{5}$ & $X_{7}$ & $X_{12}$ & $X_{13}$ & $X_{16}$ & $X_{17}$ & $\begin{array}{c}\text { Index of } \\
\text { Development }\end{array}$ & $X_{5}$ & $X_{7}$ & $X_{12}$ & $\begin{array}{c}\text { Index of } \\
\text { Development }\end{array}$ & & & & $\begin{array}{c}\text { Index of } \\
\text { Development }\end{array}$ \\
\hline Ward No. 1 & -0.35 & -0.45 & -0.38 & -0.16 & 0.77 & -0.23 & -0.80 & -0.42 & -0.21 & -0.36 & -0.98 & -0.18 & -0.60 & -0.19 & -0.97 \\
\hline Ward No. 2 & 4.60 & -0.45 & -0.38 & -0.16 & 4.18 & 3.45 & 11.24 & -0.49 & -0.21 & -0.36 & -1.05 & -0.18 & 1.75 & -0.19 & 1.37 \\
\hline Ward No. 3 & -0.35 & 1.58 & -0.38 & -0.16 & -0.31 & -0.47 & -0.09 & -0.55 & 2.09 & -0.36 & 1.18 & -0.18 & -0.60 & -0.19 & -0.97 \\
\hline Ward No. 4 & -0.10 & -0.45 & -0.38 & -0.16 & -0.31 & -0.47 & -1.86 & -0.08 & -0.21 & -0.36 & -0.64 & -0.18 & -0.60 & -0.19 & -0.97 \\
\hline Ward No. 5 & -0.19 & 0.18 & -0.38 & -0.16 & -0.31 & -0.47 & -1.32 & -0.11 & -0.21 & 2.93 & 2.62 & 1.60 & 0.18 & -0.19 & 1.59 \\
\hline Ward No. 6 & -0.35 & -0.45 & -0.38 & -0.16 & -0.31 & -0.47 & -2.12 & -0.56 & -0.21 & -0.36 & -1.13 & -0.18 & -0.60 & -0.19 & -0.97 \\
\hline Ward No. 7 & -0.11 & -0.22 & -0.38 & -0.16 & -0.31 & -0.47 & -1.65 & -0.25 & -0.21 & -0.36 & -0.81 & -0.18 & -0.60 & -0.19 & -0.97 \\
\hline Ward No. 8 & -0.35 & 2.18 & 2.71 & -0.16 & -0.31 & -0.47 & 3.60 & -0.58 & -0.21 & -0.36 & -1.14 & -0.18 & 0.05 & -0.19 & -0.32 \\
\hline Ward No. 9 & -0.35 & 0.27 & -0.38 & -0.16 & -0.31 & 0.09 & -0.85 & -0.06 & -0.21 & -0.36 & -0.63 & -0.18 & -0.60 & -0.19 & -0.97 \\
\hline Ward No. 10 & 0.03 & -0.45 & -0.38 & -0.16 & -0.31 & 0.68 & -0.58 & -0.46 & -0.21 & 1.69 & 1.02 & 1.91 & 0.32 & -0.19 & 2.04 \\
\hline Ward No. 11 & -0.35 & -0.45 & -0.38 & -0.16 & -0.31 & -0.12 & -1.77 & 2.49 & -0.21 & -0.36 & 1.92 & -0.18 & -0.60 & -0.19 & -0.97 \\
\hline Ward No. 12 & -0.23 & -0.21 & -0.38 & -0.16 & -0.31 & -0.34 & -1.63 & -0.31 & -0.21 & -0.36 & -0.88 & -0.18 & -0.60 & -0.19 & -0.97 \\
\hline Ward No. 13 & -0.15 & 0.75 & -0.38 & -0.16 & -0.31 & -0.47 & -0.71 & -0.41 & -0.21 & -0.36 & -0.98 & -0.18 & 0.88 & -0.19 & 0.51 \\
\hline Ward No. 14 & -0.08 & 0.07 & 2.71 & -0.16 & -0.31 & 1.43 & 3.67 & -0.33 & -0.21 & -0.36 & -0.90 & -0.18 & 0.70 & -0.19 & 0.32 \\
\hline Ward No. 15 & -0.35 & -0.45 & -0.38 & -0.16 & -0.31 & -0.47 & -2.12 & -0.63 & -0.21 & -0.36 & -1.19 & -0.18 & -0.07 & -0.19 & -0.45 \\
\hline Ward No. 16 & -0.35 & -0.45 & -0.38 & -0.16 & -0.31 & -0.16 & -1.81 & 0.33 & 3.28 & 2.63 & 6.24 & -0.18 & 0.88 & -0.19 & 0.50 \\
\hline Ward No. 17 & 0.49 & -0.45 & -0.38 & 3.82 & -0.31 & -0.47 & 2.70 & -0.73 & -0.21 & -0.36 & -1.30 & -0.18 & 0.40 & -0.19 & 0.03 \\
\hline Ward No. 18 & -0.08 & -0.45 & 2.68 & -0.16 & -0.31 & -0.47 & 1.21 & -0.59 & -0.21 & -0.36 & -1.15 & -0.18 & 0.04 & -0.19 & -0.33 \\
\hline Ward No. 19 & -0.04 & -0.15 & -0.38 & -0.16 & -0.31 & -0.47 & -1.50 & 0.70 & -0.21 & -0.36 & 0.14 & -0.18 & -0.60 & -0.19 & -0.97 \\
\hline Ward No. 20 & -0.35 & -0.45 & -0.38 & -0.16 & -0.31 & -0.47 & -2.12 & -0.28 & -0.21 & -0.36 & -0.85 & -0.32 & -0.68 & -0.28 & -1.29 \\
\hline Ward No. 21 & -0.35 & -0.06 & -0.38 & -0.16 & -0.31 & -0.47 & -1.72 & -0.46 & -0.21 & -0.36 & -1.02 & -0.32 & -0.68 & -0.28 & -1.29 \\
\hline Ward No. 22 & -0.35 & -0.45 & -0.38 & -0.16 & -0.31 & -0.08 & -1.73 & 2.05 & -0.21 & -0.36 & 1.48 & -0.32 & -0.68 & -0.28 & -1.29 \\
\hline Ward No. 23 & -0.35 & -0.45 & $-0,38$ & -0.16 & 1.92 & 0.99 & 1.57 & -0.56 & -0.21 & -0.36 & -1.12 & -0.18 & 1.73 & -0.19 & 1.36 \\
\hline Ward No. 24 & -0.35 & 0.38 & -0.38 & -0.16 & -0.31 & -0.47 & -1.29 & -0.21 & -0.21 & -0.36 & -0.77 & -0.18 & 2.49 & 4.75 & 7.05 \\
\hline Ward No. 25 & 1.06 & 1.72 & -0.38 & -0.16 & -0.31 & 1.77 & 3.71 & 1.40 & -0.21 & -0.36 & 0.84 & -0.32 & -0.68 & -0.28 & -1.29 \\
\hline Ward No. 26 & 0.19 & -0.45 & -0.38 & -0.16 & 0.93 & 0.61 & 0.74 & -0.07 & -0.21 & -0.36 & -0.64 & 2.77 & 0.05 & -0.19 & 2.62 \\
\hline Ward No. 27 & -0.35 & 0.07 & -0.38 & -0.16 & -0.31 & -0.47 & -1.60 & 0.77 & -0.21 & -0.36 & 0.20 & -0.32 & -0.68 & -0.28 & -1.29 \\
\hline Ward No. 28 & 0.04 & -0.45 & -0.38 & -0.16 & -0.31 & -0.47 & -1.72 & -0.53 & -0.21 & -0.36 & -1.09 & -0.32 & -0.68 & -0.28 & -1.29 \\
\hline Ward No. 29 & -0.35 & -0.45 & -0.38 & -0.16 & -0.31 & -0.47 & -2.12 & -0.12 & -0.21 & 1.12 & 0.79 & -0.32 & -0.68 & -0.28 & -1.29 \\
\hline Ward No. 30 & -0.35 & 0.35 & -0.38 & -0.16 & -0.31 & -0.19 & -1.04 & 1.15 & -0.21 & -0.36 & 0.59 & -0.18 & -0.27 & .0 .19 & -0.64 \\
\hline
\end{tabular}

Source: Computed by the Author

\section{References}

ANNUAL ADMINISTRATIVE REPORT OF BARASAT MUNICIPALITY (2008-2009), Bureau of Urban Affairs, Govt. of West Bengal, India.

DADIBHAVI, R., V. (1998), Disparities in Development of North Karnataka, Indian Journal of Regional Science, 30, 2, pp. 84-97.

DALAL, S. (2007), Infrastructural Facilities and Population Growth in Medium Towns in the States of Gujarat and Haryana, India, Regional Symbiosis, 15, pp. 103-120.

HANGARAGI, S., S. (2008), The Dimension of Inter-Taluka Disparities in the Levels of Development of Old Bijapur District of Karnataka State, Indian Journal of Regional Science, 40, 2, pp. 41-53.

HASSAN, M., I. (2007), Regional Inequality in Orissa: Some Emerging Issues, Indian Journal of Regional Science, 39, 1, pp. 40-49. 
KUMAR, S. (2009), Inter Regional and Inter District Disparities in Agricultural Development: A Study of Uttar Pradesh, Indian Journal of Regional Science, 41, 1, pp. 22-36.

MALLIKARJUN, M. (2000), Inter-Regional Disparities in Economic Development - A Study of Andhra Pradesh, Indian Journal of Regional Science, 32, 2, pp. 1-10.

MATHUR, A. (1983), Regional development and Income Disparities in India - A Sectoral Analysis, Economic Development and Cultural Change, 31, 2, pp. 475-505.

JULFIKAR, M., A., DEEPIKA V. (2010), Factors of Inter-ward Socio-Economic Disparities in Aligarh City, Uttar Pradesh, Indian Journal of Regional Science, 42, 2, pp. 40-53. MONDAL, S.,M., GARG, R., D. (2007), Urban Utility Facility Mapping and Assessment of Ward-Wise Infrastructure Development of Rishikesh - A Geoinformatics Approach, Indian Journal of Regional Science, 39, 1, pp. 111-123.

PAUL, S. (2012), Factors and Dimensions of Inter-Ward Disparities in Urban FacilityUtility Services in Burdwan City, India", Archives of Applied Science Research, 4, 3, pp. 13761388.

PAUL, S., DASGUPTA, A. (2008), Urban Facility-Utility Mapping of Krishnagar Municipality - An Appraisal of Ward-wise Infrastructure Development, Indian Journal of Landscape Systems and Ecological Studies, 31, 2, pp. 91-98.

RAO, HEMLATA (1984), Regional Disparities and Development in India, Ashish Publishing House, New Delhi.

RAO, HEMLATA (1985), Inter-State Disparities in Development in India, in Mishra, G. P. (ed.), Regional Structure of Development and Growth in India, New Delhi, 1, pp. 68-101.

SAINI, VIPIN. (2008), Growth of Towns in Different Size Classes: Study of a Less Developed Region, Indian Journal of Regional Science, 40, 1, pp. 93-97.

WILLIAMSON, J., G., (1965), Regional Inequalities and the Process of National Development: A Description of Patterns, Economic Development and Cultural Change, 12, 4, pp. 121-129.

Initial submission: 17.06.2012

Revised submission: 15.11 .2012

Final acceptance: 30.11 .2012

Correspondence: Post Graduate Dept. Geography, Krishnagar Govt. College, Krishnanagar, Nadia; West Bengal. Pin - 741101.

E-mail: suman.krish.2007@gmail.com 
